\title{
Teledetección y prospección geofísica en Veladiez. Un sector inédito de la ciudad romana de Segisamo (Sasamón, Burgos)
}

\section{Remote sensing and geophysical survey in Veladiez. A new sector of the Roman town of Segisamo (Sasamón, Burgos)}

\author{
Jesús GARCÍA SÁNCHEZ * , José Manuel COSTA-GARCÍA ${ }^{2}$
}

\footnotetext{
${ }^{1}$ Instituto de Arqueología, Mérida. CSIC-Junta de Extremadura.*Autor de contacto j.garcia@iam.csic.es

${ }^{2}$ GIR Hesperia. Departamento de Prehistoria, Historia Antigua y Arqueología. Universidad de Salamanca. jm.costagarcia@usal.es
}

https://doi.org/10.17979/cadlaxe.2021.43.0.8726 recibido: 13/10/2021 aceptado: 9/11/2021

\begin{abstract}
The authors have paid special attention to the study of the Roman city of Segisamo (Sasamón) within the framework of the project that analyses the archaeological landscapes in the transition between the Iron Age and the Roman period in the Odra-Pisuerga region (Burgos). In 2019, some aerial photographs allowed the detection and documentation of archaeological structures in the city's northwest sector. Further UAV-derived aerial (RGB and NIR) and geophysics surveys have taken place since then. This non-destructive approach has made it possible to recover an unknown sector of the Roman city of Segisamo and put forward new hypotheses about the city's limits in ancient times.
\end{abstract}

Keywords: remote sensing, geophysical prospection, Ground-Penetrating Radar, UAV, aerial survey, Roman urbanism 


\section{Resumen}

En el marco del proyecto que analiza los paisajes arqueológicos en la transición entre la Edad del Hierro y época romana en la comarca del Odra-Pisuerga hemos prestado especial atención al estudio de la antigua ciudad romana de Segisamo (Sasamón). Desde 2019, a partir de una primera cobertura aérea, hemos sido capaces de reconocer en el sector noroeste de la ciudad la presencia de estructuras arqueológicas que han sido objeto de sucesivas prospecciones aéreas usando UAVs (RGB y NIR) y geofísicas. Esta aproximación no destructiva ha permitido recuperar un sector desconocido de la ciudad romana de Segisamo y plantear nuevas hipótesis acerca de los límites de la ciudad.

Palabras clave: teledetección, prospección geofísica, georradar, fotografía aérea, UAV, urbanismo romano 


\section{INTRODUCCIÓN}

La ciudad romana de Segisamo se ubica en gran parte bajo el actual pueblo de Sasamón, situado a unos $30 \mathrm{~km}$ al oeste de Burgos. No obstante, la antigua urbs rebasa los límites del caserío actual tanto hacia el norte como hacia el oeste y el suroeste. Es en esta zona donde se desarrolla la investigación arqueológica no invasiva de la ciudad romana. Iniciada en 2008 (GARCÍA SÁNCHEZ, 2016), en el marco de la prospección y estudio off-site del llamado ager Segisamonesis (GARCÍA SÁNCHEZ, 2018; GARCÍASÁNCHEZ y CISNEROS, 2013), continúa desde 2017 bajo el proyecto Warscapes, que estudia la transición de los paisajes arqueológicos en la comarca del Odra-Pisuerga (Burgos) entre la Edad del Hierro y época romana altoimperial (ss. I a.C.-III d.C.) (GARCÍA SÁNCHEZ y COSTA-GARCÍA, 2020) (Figura 1).

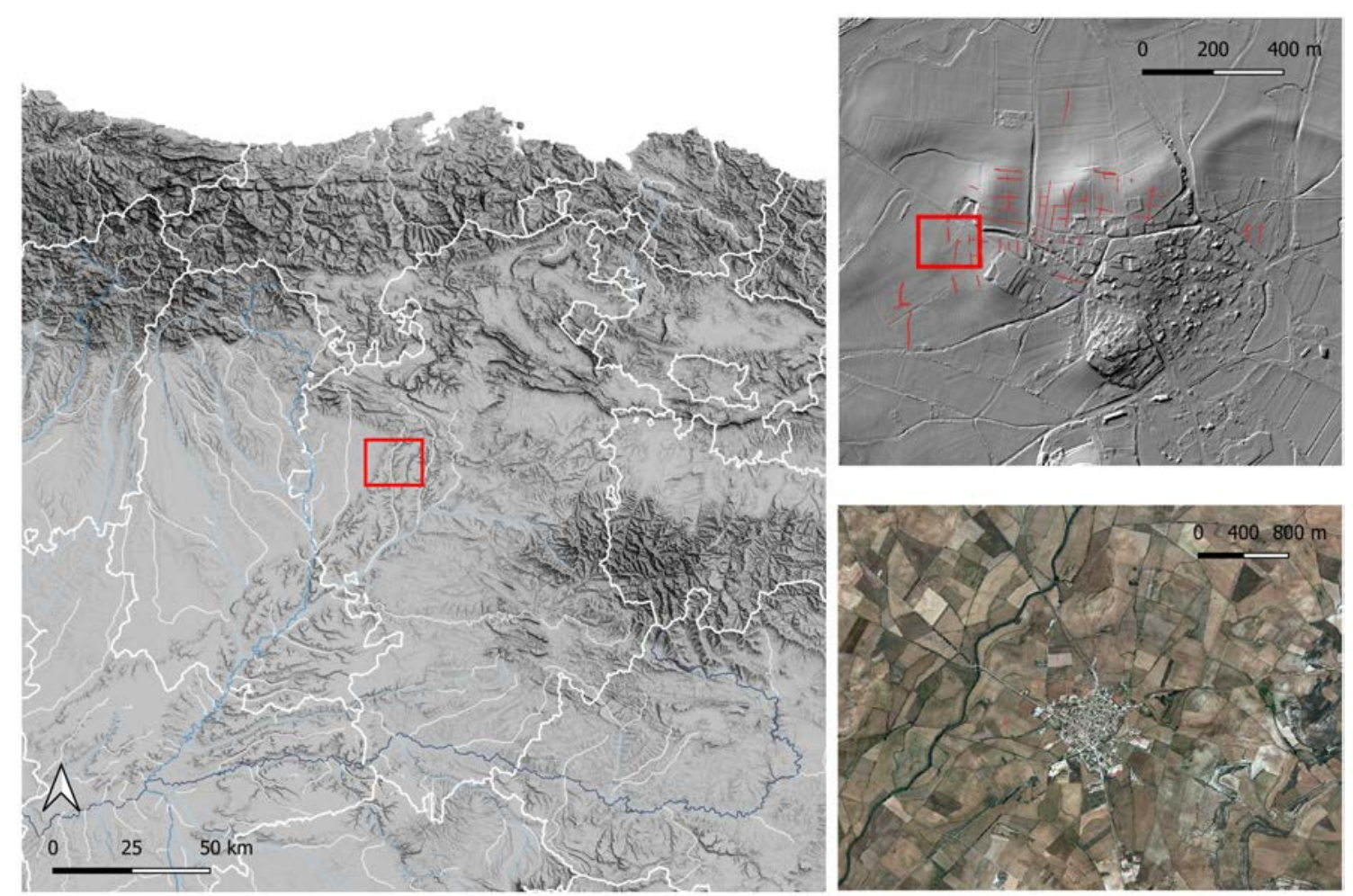

Figura 1. Izquierda: zona de estudio ubicada en la provincia de Burgos. Derecha abajo: localidad de Sasamón. Derecha arriba: entramado urbano de Segisamo.

En la década de 1970, J. A. Abásolo y R. García (ABÁSOLO y GARCÍA, 1993) plantearon una serie de sondeos arqueológicos en diferentes puntos de la ciudad antigua: Las Sernas, Tarreros de Villasidro, El Arquillo y el interior de la colegiata de la iglesia de Santa María. Estos sondeos permitieron documentar diversas estructuras y elementos de la cultura material fechables entre los siglos I y III d.C. El hallazgo más monumental en este contexto fue el descubrimiento de un mosaico romano datado en el siglo III d.C. y que hoy se encuentra custodiado en la iglesia de Santa María de Sasamón. Desde entonces, algunos de los elementos que formaban parte del trazado 
urbanístico romano (ABÁSOLO, 1975; ABÁSOLO y GARCÍA, 1993; DIDIERJEAN y ABÁSOLO, 2007) han podido documentarse con más detalle mediante prospección geofísica o a través del análisis en superficie de los restos aún conservados, como ocurre por ejemplo con las llamadas termas de Sasamón (GARCÍA SÁNCHEZ, 2020).

Sin embargo, el área de Veladiez situada al sur de la actual carretera a Villasidro, al noroeste de Sasamón, no había sido considerada por ABÁSOLO y GARCÍA (1993: 12) como parte de la ciudad romana. Las fotografías aéreas tomadas por diversos investigadores han permitido replantear esta hipótesis (DEL OLMO, 2006; DIDIERJEAN y ABÁSOLO, 2007; GARCÍA SÁNCHEZ, 2012). Cabe proponer ahora la existencia aquí de un barrio integrado en el planeamiento urbanístico antiguo donde las calles se ordenarían de acuerdo con un módulo de 1 por 2 actus con al menos dos orientaciones diferentes.

El presente trabajo se basa en el empleo de métodos y técnicas de investigación no destructivas, principalmente teledetección aérea mediante UAVs (Unmanned Aerial Vehicles) y prospección geofísica. Este tipo de métodos está perfectamente testado y asimilado como fuente de datos arqueológicos para el estudio de la antigüedad clásica, tanto a pequeña escala como para la documentación extensiva de ciudades de cronología romana, caso de Faleri Novii y Potentia (Verdonck et al., 2020; Vermeulen et al., 2006) en Italia o Ammaia (Verdonck et al., 2012), en Portugal, entre otros muchos. En España se han producido recientes investigaciones en Libia (Herramélluri, La Rioja) (ARIÑO et al., 2019) Asta Regia (Jerez de la Frontera, Cádiz) (LAGÓSTENA BARRIOS, 2021), Italica (Santiponce, Sevilla) (HIDALGO PRIETO et al., 2018), Munigua (Villanueva de Río y Minas, Sevilla) o Termes (Tiermes, Soria) (TEICHNER et al., 2021) empleando métodos geofísicos variados. En todos estos casos se ha considerado la combinación de georradar (GPR) y magnetometría para la comparación de resultados y visibilización de diferentes elementos arqueológicos sensibles a los distintos métodos de exploración. En algunos casos también se han desarrollado originales usos de las coberturas fotográficas satelitales recientes. Clunia (Coruña del Conde-Peñalba de Castro, Burgos) (FIZ et al., 2021), capital del conventus Cluniensis al que pertenecería jurídicamente la antigua Segisamo, es buen ejemplo de ello.

\section{METODOLOGÍA}

Para este caso de estudio hemos empleado dos métodos principales: sucesivas coberturas fotográficas cenitales y oblicuas (Tabla 1) y levantamientos fotogramétricos con recurso a UAVs llevado a cabo entre los años 2019 y 2021, y una prospección geofísica empleando GPR realizada a finales de $2019^{1}$. La combinación de ambas técnicas ha permitido un exhaustivo análisis del territorio y la detección de diversos

\footnotetext{
${ }^{1}$ Estas acciones se enmarcan en los siguientes proyectos arqueológicos: Prospección geofísica en el pago de Veladiéz (Sasamón, Burgos) (Núm. Expte. AA-286/2019-065); Prospección en el Cerro de Castarreño y prospección geofísica (Núm. Expte. 20/096-BU); Prospección y documentación del patrimonio arqueológico mediante fotografía aérea (Núm. Expte. AA-200 / 2021-050).
} 
elementos arqueológicos que pueden relacionarse con nuevos sectores de la ciudad romana.

Tabla 1. Coberturas fotográficas y fotogramétricas con recurso a UAVs.

\begin{tabular}{|c|c|c|c|c|c|c|c|c|c|c|}
\hline Cobertura & Plataforma & Fecha & $\begin{array}{c}\text { Fabri- } \\
\text { cante }\end{array}$ & Modelo & $\begin{array}{c}\text { Senso- } \\
\text { res }\end{array}$ & $\begin{array}{c}\text { Punto } \\
\text { F }\end{array}$ & $\begin{array}{c}\text { Exposi- } \\
\text { ción }\end{array}$ & Iso & $\begin{array}{c}\text { Distancia } \\
\text { Focal }\end{array}$ & $\begin{array}{c}\text { Apertura } \\
\text { Max }\end{array}$ \\
\hline $\mathbf{1}$ & $\begin{array}{c}\text { Phantom } \\
\text { 3SE }\end{array}$ & $06-08.06 .2019$ & DJI & $\begin{array}{c}\text { Sensor 1/2.3" CMOS, } \\
12 \text { Mp, }\end{array}$ & RGB & $f / 2.8$ & $1 / 1032 \mathrm{~s}$ & 100 & $4 \mathrm{~mm}$ & 2.97 \\
\hline $\mathbf{2}$ & Mavic air & 08.06 .2020 & DJI & $\begin{array}{c}1.2 / 3 " \text { CMOS } \\
\text { Píxeles efectivos: } 12 \\
\text { MP }\end{array}$ & RGB & $\mathrm{f} / 2.8$ & $1 / 75 \mathrm{~s} 2$ & 112 & $4 \mathrm{~mm}$ & 2.971 \\
\hline $\mathbf{3}$ & Mavic 2 Pro & $08-09.06 .2021$ & DJI & Hasselblad L1D-20c & RGB & $\mathrm{f} / 5.6$ & $1 / 400 \mathrm{~s}$ & 100 & $10 \mathrm{~m}$ & 2.971 \\
\hline 4A & $\begin{array}{c}\text { Phantom } \\
\text { 3SE }\end{array}$ & 10.06 .2021 & DJI & $\begin{array}{c}\text { Sensor 1/2.3" CMOS, } \\
12 \text { Mp, }\end{array}$ & RGB & $\mathrm{f} / 2.8$ & $1 / 443 \mathrm{~s}$ & 100 & $4 \mathrm{~mm}$ & 2.97 \\
\hline 4B & $\begin{array}{c}\text { Phantom } \\
\text { 3SE }\end{array}$ & 10.06 .2021 & MAPIR & Survey3W_NGB & NIR-G-B & $\mathrm{f} / 2.8$ & $1 / 495 \mathrm{~s}$ & 50 & $3 \mathrm{~mm}$ & 3 \\
\hline
\end{tabular}

\subsection{Prospección aérea}

La fotogrametría mediante drones se ha convertido en una herramienta de uso extendido en la arqueología del paisaje (O'DRISCOLL, 2018; WAAGEN, 2019) y constituye una de las principales aproximaciones al estudio de la ciudad romana de Segisamo. La cobertura de los sectores no afectados por el caserío actual, dedicados principalmente al cultivo del cereal, permite actualizar el mapa arqueológico de la ciudad, así como monitorizar posibles afecciones producidas por el laboreo agrícola o por la actividad del detectorismo ilegal en la región.

Durante la primera cobertura en Veladiez nos encontramos unas inmejorables condiciones para la prospección aérea. En el momento de realizarse el vuelo (6-8 de junio de 2019) el cereal se encontraba en un punto óptimo de maduración. El crecimiento diferencial y el contraste cromático permitían reconocer la presencia de estructuras arqueológicas (DRIVER et al., 2020). Reconocido el potencial de esta área, realizamos un segundo vuelo con el fin de proceder a su levantamiento fotogramétrico. Estas acciones permitieron documentar en Veladiez la vía romana que conectaba Segisamo con Pisoraca (Herrera de Pisuerga, Palencia) (MORENO GALLO, 2011) y varias estructuras en su entorno (GARCÍA SÁNCHEZ y COSTA-GARCÍA, 2020).

Cuando se llevó a cabo una nueva campaña de prospecciones aéreas en 2020, el área de estudio se dedicaba a forraje. Este cultivo bajo y arbustivo impide el reconocimiento de marcas en el terreno derivadas de la presencia de estructuras arqueológicas (cropmarks), por lo que la prospección se orientó hacia parcelas aledañas en las cuales pudieron identificarse otras evidencias del trazado urbano de época romana.

La tercera cobertura, realizada el 8-9 de junio de 2021 (Figura 2), se integra en un proceso más amplio cuyo objetivo fue la realización de un levantamiento fotogramétrico general del entorno del actual núcleo urbano de Sasamón. Con ello pretendíamos actualizar la cartografía urbana de época romana y seleccionar nuevas áreas de intervención para la prospección geofísica. 


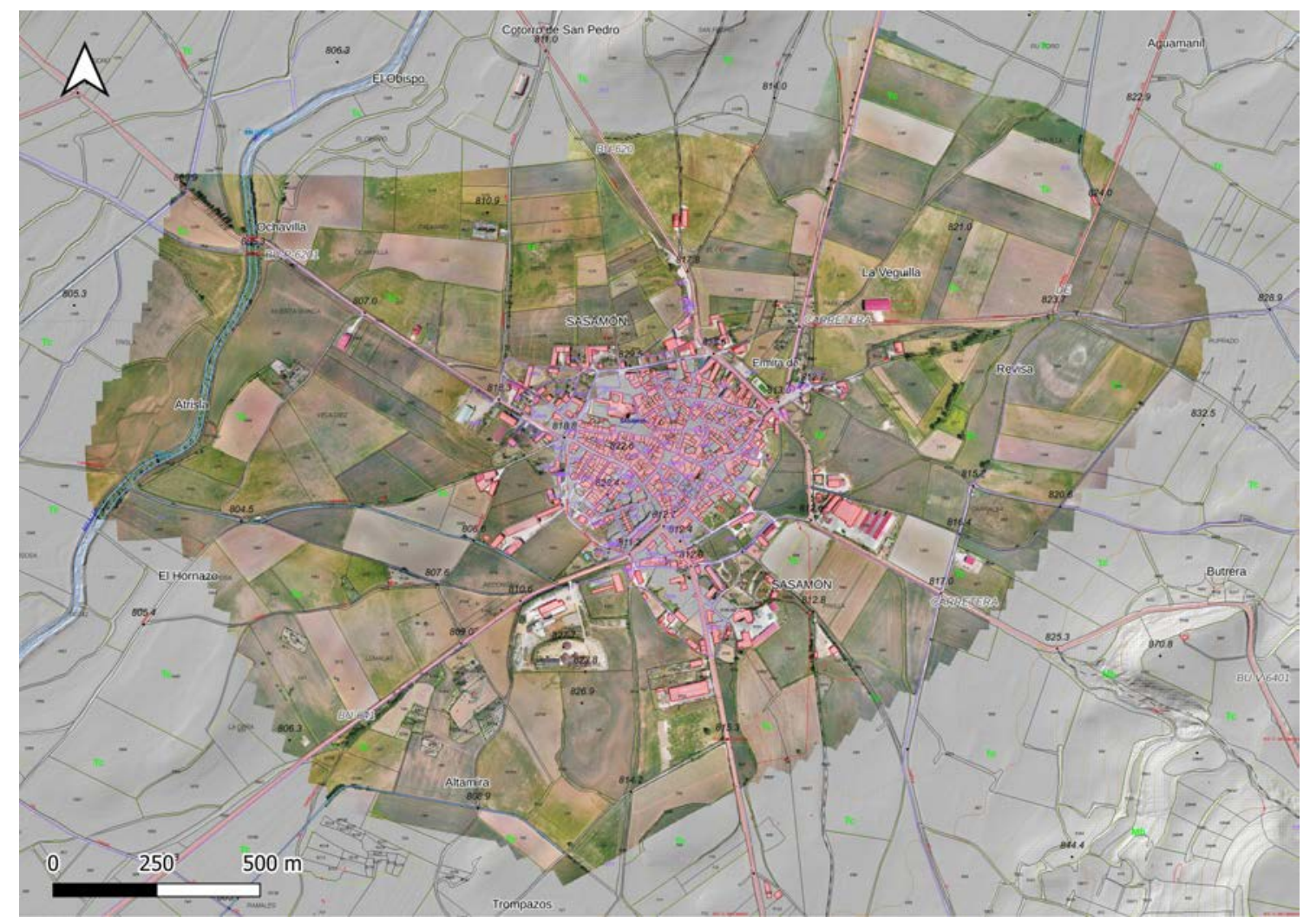

Figura 2. Cobertura ortofotográfica de 2021.

Finalmente, la cuarta cobertura tuvo como objetivo explorar las posibilidades de la teledetección y creación de índices basados en el espectro infrarrojo. Esta se realizó el día 9 de junio de 2021 en RGB (espectros visibles rojo-verde-azul) y NIR-G-B (infrarrojo cercano verde-azul) mediante el empleo de una cámara MAPIR 3W acoplada a la plataforma del Phantom 3SE. El proceso de la imagen se realizó mediante la calibración de la reflectancia de las imágenes, al tiempo que las ortofotografías georreferenciadas tuvieron lugar en Metashape con un procesado posterior en QGIS.

De cara a mejorar los análisis, se combinó la ortofotografía en color RGB con la ortofotografía realizada con el sensor NIR-G-B MAPIR 3W tomadas en 2021. Con estos productos se calcularon diversos índices (LASAPONARA y MASINI, 2011; SALGADO CARMONA et al., 2020) de vegetación haciendo hincapié en las posibilidades que brinda el espectro infrarrojo (VERHOEVEN, 2012) para la detección de estructuras soterradas a través de cambios locales en la reflectancia de energía de los cultivos. En este contexto en concreto, el infrarrojo cercano aporta información sobre el estado morfológico y fisiológico del cultivo más allá de los límites perceptibles por el ojo humano. Para este estudio analizamos la banda del infrarrojo cercano NIR de 850 $\mathrm{nm}$, así como los resultados de un cálculo del NVDI (Normalized Difference Vegetation Index) y el índice PSRI (Plant Senescence Reflectance Index), que ya habían deparado interesantes resultados en la investigación del castro vetón de Villasviejas de Tamuja (SALGADO CARMONA et al., 2020). 


\subsection{Prospección geofísica GPR}

La prospección geofísica de desarrolló al sur de la carretera que comunica Sasamón con Villasidro, una zona con gran potencial arqueológico situada en las inmediaciones de los pagos de Arquillos y La Serna, investigados por Abásolo y García. No obstante, el área de Veladiez no fue inicialmente considerada parte de la ciudad (ABÁSOLO, 1975) hasta que posteriores fotografías áreas oblicuas de DIDIERJEAN y ABÁSOLO (2007) mostraron la extensión de la trama urbana en esta zona. La primera cobertura realizada con medios propios, entre el 6 y 8 de junio de 2019, aumentó exponencialmente los datos disponibles sobre este sector (GARCÍA SÁNCHEZ y COSTA-GARCÍA, 2020), sentando las bases para la prospección geofísica.

Durante la intervención de 2019 se empleó el método de prospección geofísica denominado Radar de Penetración Terrestre o Ground-Penetrating Radar (CONYERS, 2004; SCHMIDT et al., 2015). Este permite la detección de cambios en la composición de los materiales soterrados gracias a la variabilidad en sus características dieléctricas. Empleamos un sistema monoestático (una antena emisora y una antena receptora) transportado sobre un sistema móvil (Smart Car de la empresa Sensor \& Software) desde el que se controlaron los trabajos. La principal ventaja de este sistema es que parte del pulso electromagnético emitido por el sensor vuelve al receptor cada vez que se produce un cambio de material en el subsuelo, parte se dispersa y parte continua su trayectoria independientemente de las capacidades conductivas de los materiales. Toda esta información se recoge en forma de radargramas individuales que pueden interpolarse para ofrecer una visión tridimensional del subsuelo.

De acuerdo con anteriores experiencias de trabajo, la calidad de los datos generados por un sensor monostático de $250 \mathrm{mhz}$ (Tabla 2) es suficientemente buena como para plantear interpretaciones de estructuras soterradas (SEREN et al., 2007). La zona de trabajo se ubica en la unidad estructural de la campiña, compuesta por arenas y arcillas con niveles discontinuos de areniscas y conglomerados (ARCE DUARTE, 1997). Aunque la cercanía a una zona inundable y a la presencia de arcillas podría suponer dificultades a la hora de obtener datos de buena calidad, los resultados han sido buenos, en parte debido al contexto arenoso y al estado seco del área de prospección en el momento de desarrollarse la intervención.

Tabla 2. Especificaciones técnicas del equipo geofísico empleado.

\begin{tabular}{|l|l|}
\hline \multicolumn{1}{|c|}{ Categoría } & \multicolumn{1}{c|}{ Noggin $\circledast 250 \mathrm{mhz}$} \\
\hline Tamaño & $63 \times 41 \times 23 \mathrm{~cm}$ \\
\hline Peso & $7.3 \mathrm{~kg}(12.5 \mathrm{lbs})$ \\
\hline Centro de la Frecuencia & $250 \mathrm{MHz}$ \\
\hline -6dB Bandwidth & $125-375 \mathrm{MHz}$ \\
\hline Shielding Front to Back & $>20 \mathrm{~dB}$ \\
\hline Ventana de tiempo máximo & $2,000 \mathrm{~ns} @ 0.4 \mathrm{~ns} / \mathrm{pt}$ \\
\hline Profundidad máxima Setting* & $100 \mathrm{~m}(328 \mathrm{ft})$ \\
\hline
\end{tabular}


Se prospectaron 13 cuadros de dimensiones variables que permitieron cubrir un total de $5113 \mathrm{~m}^{2}$ en el área donde se habían identificado las estructuras arqueológicas detectadas, en particular sobre el trazado de la vía que parte de Segisamo hacia Pisoraca, paralela a la actual carretera de Villasidro.

Los datos recopilados por el sensor Noggin 250 se georreferenciaron automáticamente gracias al receptor GPS Topcon instalado en el SmartCart sobre el eje vertical del sensor. De forma simultánea a los trabajos de prospección y para mayor precisión de los mismos, los vértices de los cuadros -grids- de prospección se georreferenciaron mediante el uso de un GPS Leica Zeno 20 con corrección subcentimétrica GNSS del Instituto Geográfico Nacional.

El procesamiento de los datos de esta zona se realizó tomando como referencia la rutina elaborada por el IMS-Forth y A. Sarris (2020) durante la prospección con un equipamiento similar de Lechaion, en el Peloponeso (Grecia).

\section{RESULTADOS}

En el siguiente apartado exponemos los resultados de prospección aérea y la prospección geofísica. Ambos métodos confirman la existencia de un complejo residencial al oeste de la ciudad y los posibles límites de la misma en este sector coincidiendo con el trazado de una vía romana en dirección Pisoraca (Herrera de Pisuerga).

\subsection{Prospección aérea}

A partir de las coberturas fotográficas cenitales realizadas mediante UAVs se han generado varios levantamientos fotogramétricos empleándose el software Metashape, basado en la Fotogrametría Digital Automatizada y en algoritmos de Reconstrucción en 3D de Alta Densidad a partir de Múltiples Puntos de Vista. Esto nos ha permitido exportar ortofotografías (Figura 3) y Modelos Digitales de Superficie (MDS) de alta resolución (3-10 cm). Los primeros modelos, elaborados en 2019, nos permitieron ver con claridad la vía Segisamo-Pisoraca y definir a grandes rasgos varios bloques de planta cuadrangular con posibles espacios abiertos (patios).

Las ortofotografías e índices generados NDVI y PSRI (Figuras 4 y 5) muestran la disposición de un edificio de planta cuadrangular donde destaca una cabecera ubicada sobre una estancia o patio también de traza rectangular. En torno a la cabecera y al patio se disponen varias estancias. El índice NDVI muestra una vegetación menos vigorosa en la zona, quizás relacionado con la presencia de pavimentos o derrumbes. A una escala menor, también se pueden observar las calles de la ciudad en orientación nortesur.

Otro de los resultados más interesantes de la teledetección fue la identificación de un trazado oblicuo que rodea a las estructuras constructivas. Este no sigue la orientación 
del trazado urbano, por lo que no puede interpretarse como parte del mismo. La principal hipótesis interpretativa es que constituyese el límite oeste de la ciudad, definido quizá a partir de alguna estructura o desnivel. Pese a las sucesivas coberturas fotográficas, no hemos documentar otros elementos constructivos que formasen parte del urbanismo antiguo a partir de este punto. Como veremos más adelante, este trazado oblicuo también es visible en los datos de georradar. Más que una muralla, en este caso podríamos estar ante un gran foso que sirve como límite al núcleo urbano, una solución que encuentra paralelos en la fossa limitalis mencionada por los agrónomos latinos (GARCÍA SÁNCHEZ, 2018).

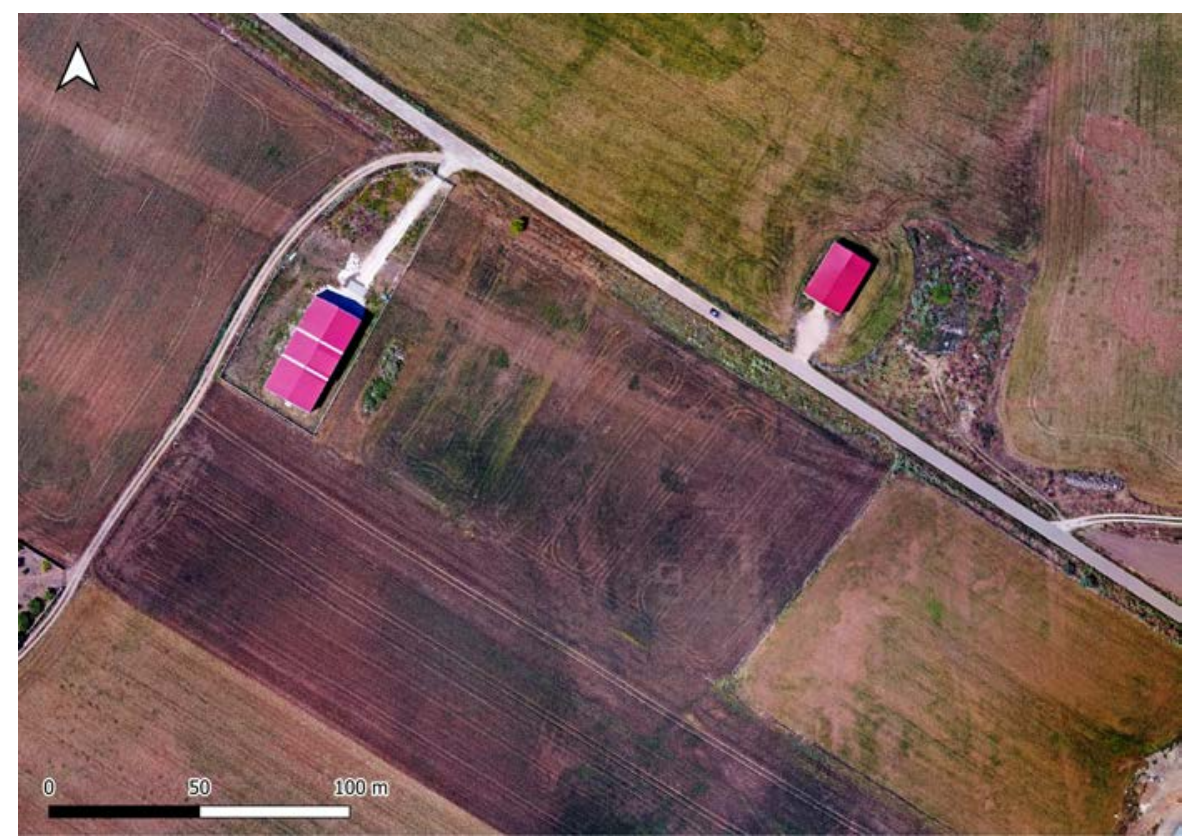

Figura 3 Ortofotografía de detalle en Veladiez. Cobertura 3 (RGB-2021). Apréciese el trazado de la vía en dirección ESE-ONO así como la presencia al sur de la misma de varias estructuras soterradas.
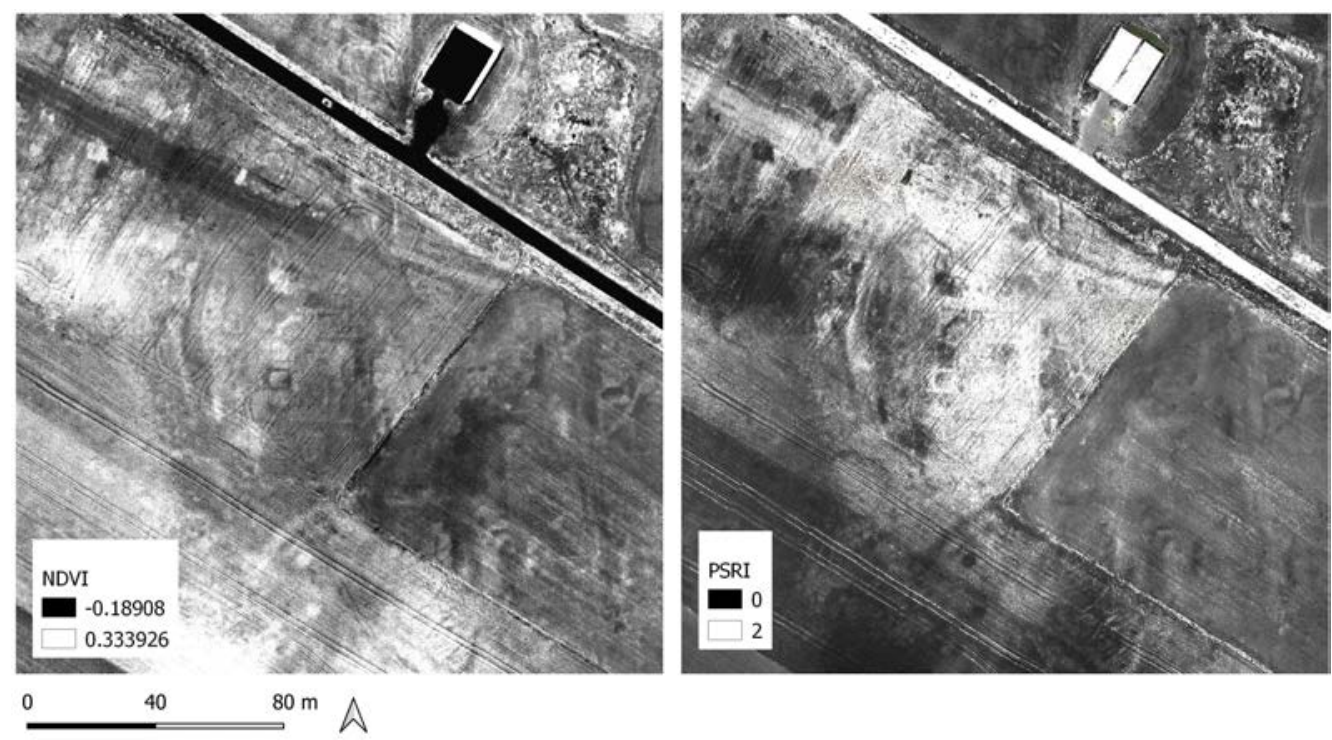

Figura 4 Comparación de índices NDVI y PSRI. 


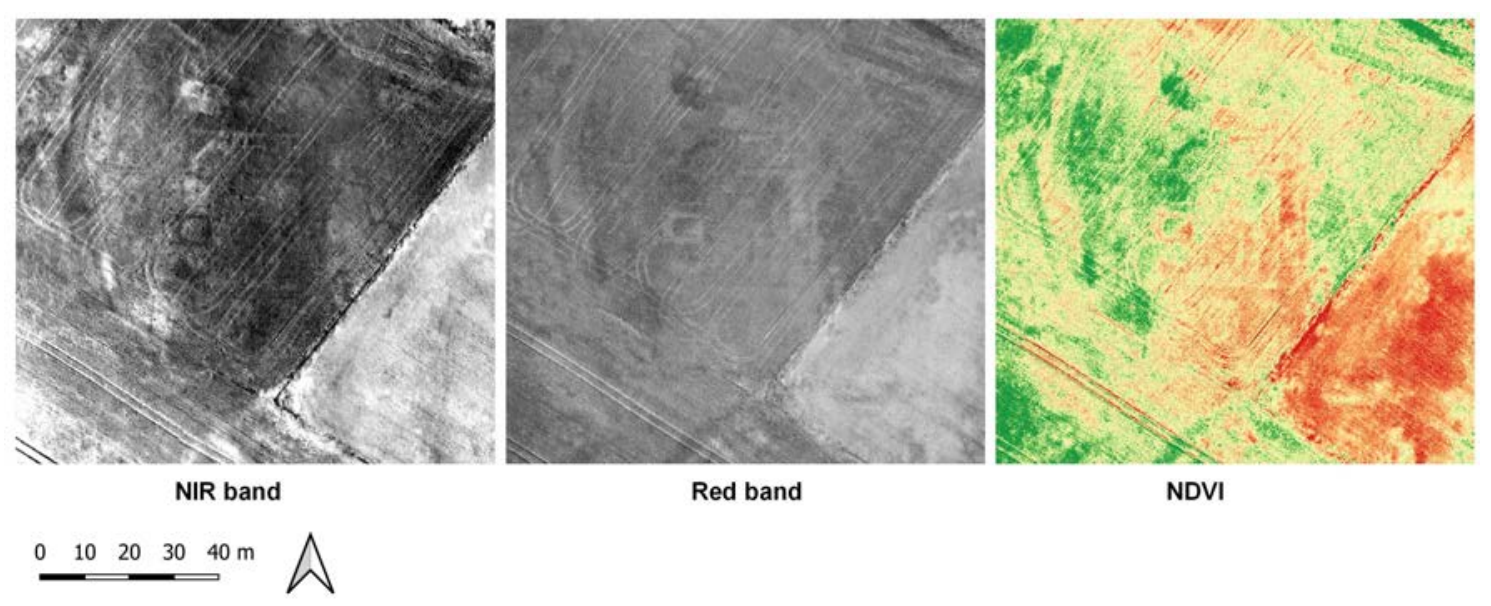

Figura 5 Comparación de bandas aisladas e índice NDVI.

\subsection{Prospección geofísica}

Los resultados de la prospección geofísica mediante georradar en Veladiez han permitido visualizar de forma mucho más clara las estructuras ya reconocidas en la fotografía aérea. Estas se corresponden con edificios de tipo urbano delimitados por ejes viarios: el más importante es la ya mencionada vía Segisamo-Pisoraca, a partir de la cual otros espacios de tránsito menores se disponen en dirección norte-sur. La prospección geofísica ha permitido documentar tanto estructuras lineales que se corresponden con muros como otros espacios abiertos que en algunos casos parecen conservar pavimentos.

Los edificios identificados con detalle son tres (Figura 6). El primero ha sido interpretado como una domus o residencia unifamiliar urbana, dotada de un peristilo al que se accede a través de un pórtico columnado similar al visto en otros edificios urbanos de época romana imperial y que se adapta a los modelos de "casa de peristilo" expuesta por BELTRÁN (2003: 26). El segundo y tercer edificio se localizan entre la domus con peristilo y la vía Segisamo-Pisoraca. Aquí no hemos detectado ningún elemento central, aparte de algún pequeño patio o atrio - aparentemente sin columnas perimetrales-, motivo por el que creemos que se trata de complejos residenciales desarrollados en altura y lo hemos denominado insulae 1 y 2.

Finalmente, la reconstrucción de la planta de estas estructuras nos permite identificar la probable división de este espacio en cuatro bloques (Figura 7): el primero es la mencionada domus con peristilo; el segundo y el tercero comprenden las insulae 1 y 2 ; y el cuarto bloque se ubica al sur de la domus principal, no ha sido prospectado de forma completa pero puede intuirse una serie de espacios abiertos hacia hacía una de las calles del trazado urbano, la misma a la que se abre el pórtico de la domus y la insula 2. 

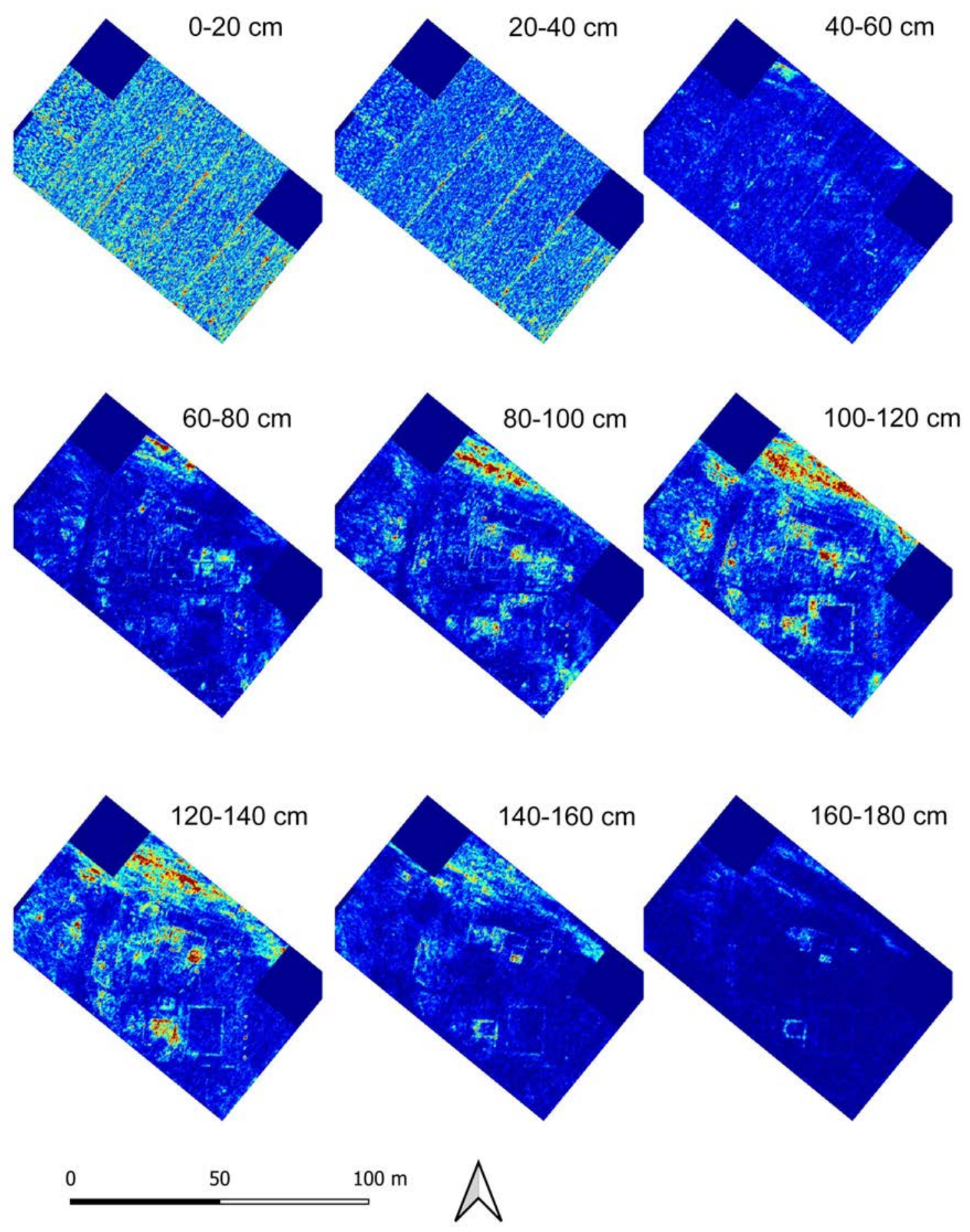

Figura 6 Cortes de profundidad en la prospección GPR de Veladiez

.Del mismo modo, inmediatamente al sur del bloque denominado domus de peristilo podemos observar el arranque de nuevos muros que podrían definir otro bloque prospectado de forma parcial. 


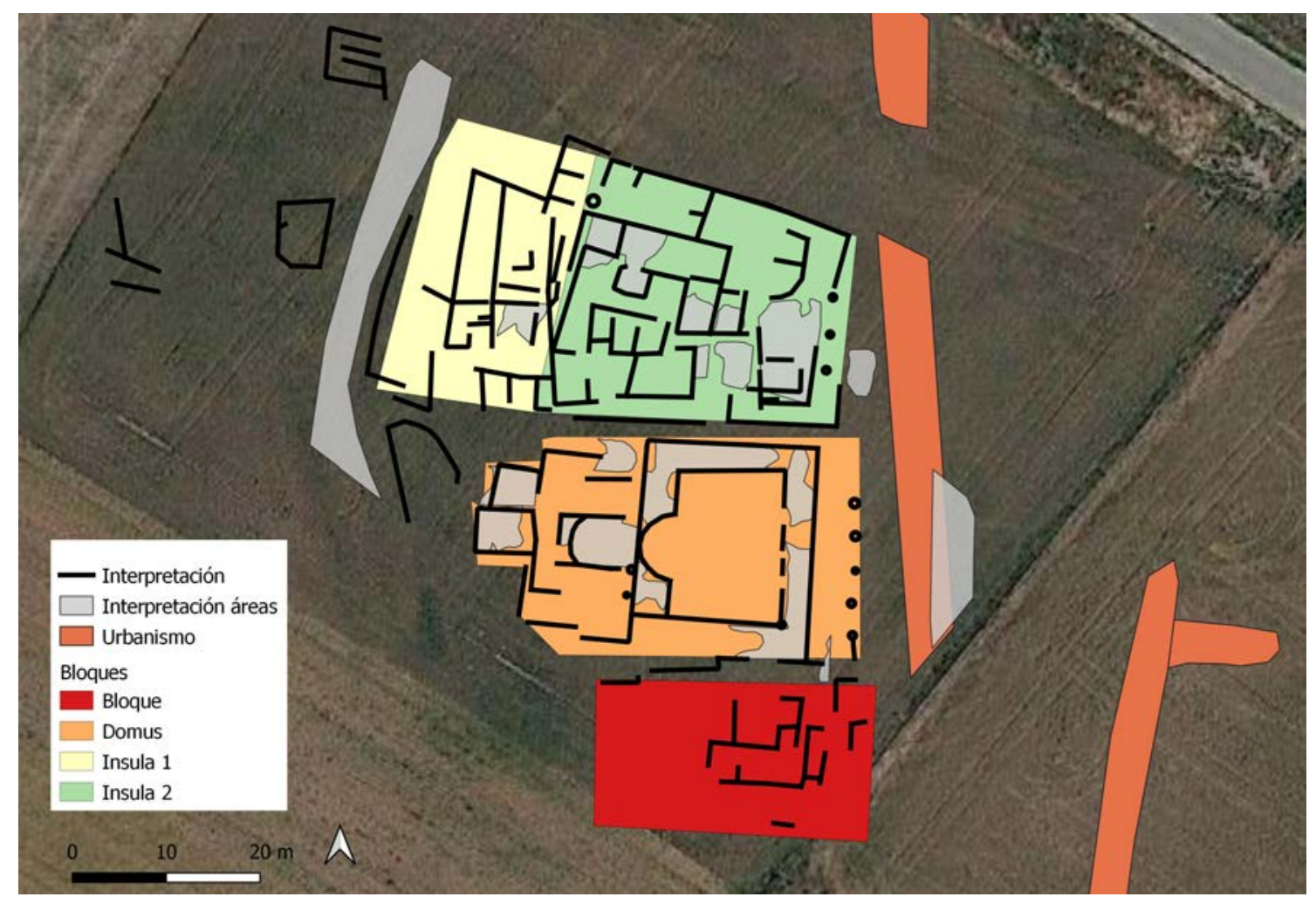

Figura 7 Interpretación de estructuras y bloques identificados.

Durante la prospección con georradar no se ha procedió a la recogida de material arqueológico en superficie. No obstante, se observó una gran acumulación de material constructivo de todo tipo -incluyendo pestañas de tégula e ímbrices (tejas planas y curvas); ladrillos de construcción, varios de ellos totalmente calcinados; y algunos fragmentos de ímbrice o canalización cerámica machihembrada- Se han observado también algunos materiales arqueológicos ya conocidos en otras áreas de Sasamón como pesas de telar, cerámica común romana, pequeños vidrios y también varios fragmentos de terra sigillata hispánica lisa con engobe de buena calidad y muy adherente. Entre las formas observadas destaca algún plato llano y formas de tendencia hemisférica como Ritt. 8, Drag, 37 o Drag. 29.

\subsection{Análisis de las estructuras documentadas}

\subsubsection{Domus de peristilo}

Particular atención requiere el edificio denominado como domus de peristilo (Figura 8). Este edificio coincide con la estructura interpretada a través de la foto aérea y su hallazgo permite la documentación del primer edificio de este tipo en el solar urbano de Segisamo. 


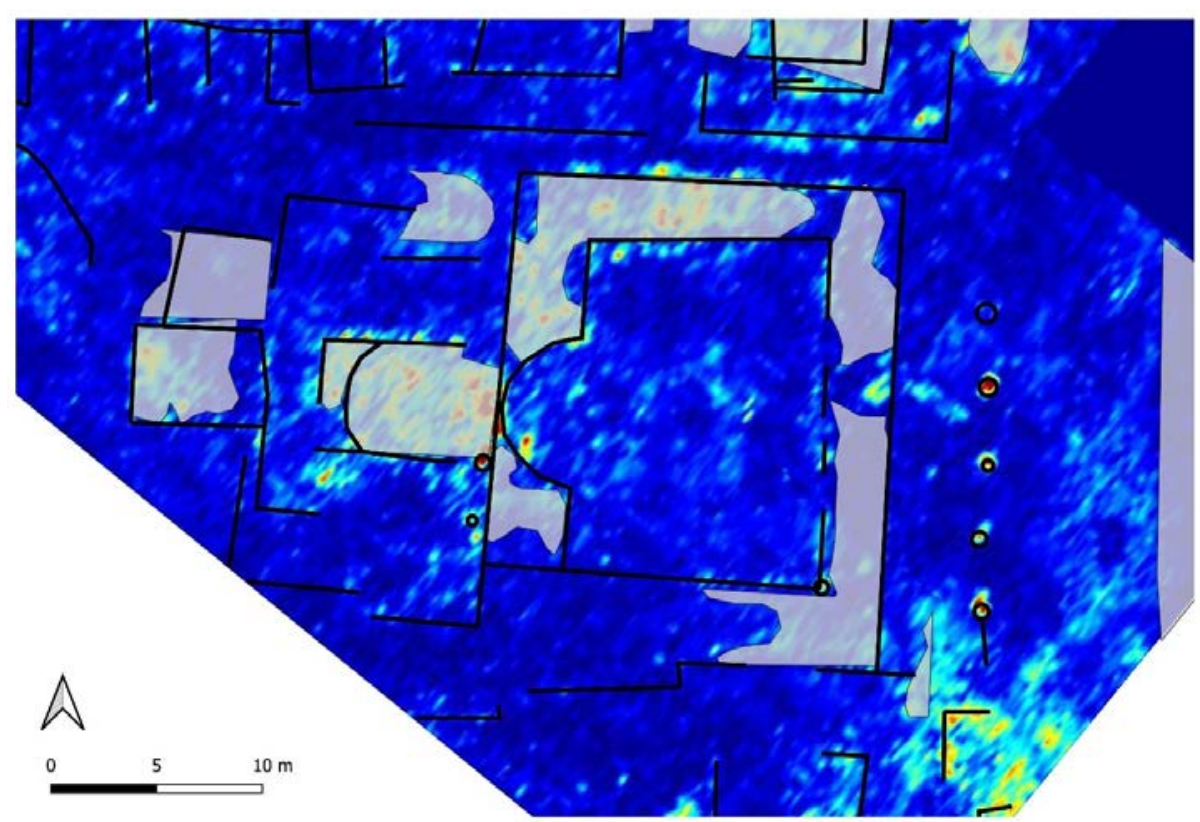

Figura 8 Interpretación de la domus de peristilo a $80 \mathrm{~cm}$ bajo la superficie

Este edificio se documenta de forma clara a partir del corte en profundidad de $60 \mathrm{~cm}$, pero su planimetría se reconoce mejor en los de 100-120 y 120-140 cm. Así, se desarrolla alrededor de un amplio patio interior columnado de $16 \times 11$ m rodeado por un pasillo de 2,9 m de anchura (10 pies romanos) que amplía la estructura hasta los 22 x 19 m. A juzgar por la lectura de los datos GPR, parte de este pasillo conservaría el pavimiento. En su sector oeste, nos encontramos con una estructura hemisférica abierta hacia el patio, posiblemente dispuesta a modo de exedra. Inmediatamente al oeste de la estructura hemisférica/ exedra se dispone una habitación cuadrangular de 8 x $5 \mathrm{~m}$ que también podría conservar su pavimento. Siguiendo los modelos tradicionales de casas hispanorromanas podríamos suponer que se trata del tablinium u oficina del propietario de la domus (desde este espacio se atenderían los negocios y se recibiría a los clientes). A izquierda y derecha de este espacio se abren otras dos habitaciones.

Otro de los principales elementos de la domus es su fachada hexástila (de seis columnas), situada al este de la domus. Seguramente se dispusiese en forma de pórtico abierto hacia la calle, que en este punto se ordena en sentido norte-sur.

\subsubsection{Insulae 1 y 2}

Ubicada entre la domus y la calzada romana - que se describirá en el apartado siguiente-, se ha definido un nuevo bloque que hemos denominado insulae 1 y 2 (Figura 9). Esto se debe a que el conjunto puede dividirse en dos edificios autónomos unidos por una pared medianera Estas insulae se corresponden con viviendas multifamiliares desarrolladas en altura y ocupadas por individuos de estracción social generalmente baja. Asimismo, podían contar en su planta baja con locales comerciales. 
La insula 1 está situada al oeste tiene unas medidas de $27.8 \times 16,1 \mathrm{~m}$ de lado. En su parte meridional puede tener compartimentos abiertos a un espacio abierto que lo separa de la domus. En la zona interior del edificio podemos distinguir dos estancias de aproximadamente $4 \times 5 \mathrm{~m}$ seguidas de naves de tendencia rectangular de unos $14 \mathrm{~m}$ de largo. Aunque no se han identificado elementos que hayan servido para ordenar las estancias, la presencia de pavimentos podría indicarnos la existencia de zonas de tránsito a alrededor de las cuales se ordenaría el hábitat (Figura 9).

La insula 2 presenta una planta más compleja, encajándose en un espacio de 29,7 x 20,13 m de lado. Al igual que sucede con la insula 1, se adapta al espacio entre la calzada romana y la domus. Al interior observamos varias estancias de forma abigarrada, aunque de trazado rectangular. Además, algunas zonas conservan pavimentos. El sector este presenta también un frente porticado con tres columnas abiertas hacia una de las calles que discurren en sentido norte-sur. El sistema de organización trapezoidal, quizás dividido en dos bloques, se asemeja a la casa del Vaso Fálico excavada en Conimbriga (ALARÇÃO y ETIENNE, 1977; BELTRÁN, 2003: 89). En este caso, el frente porticado que se abre a la calle podría considerase un soportal que alojaría dependencias de tipo comercial.

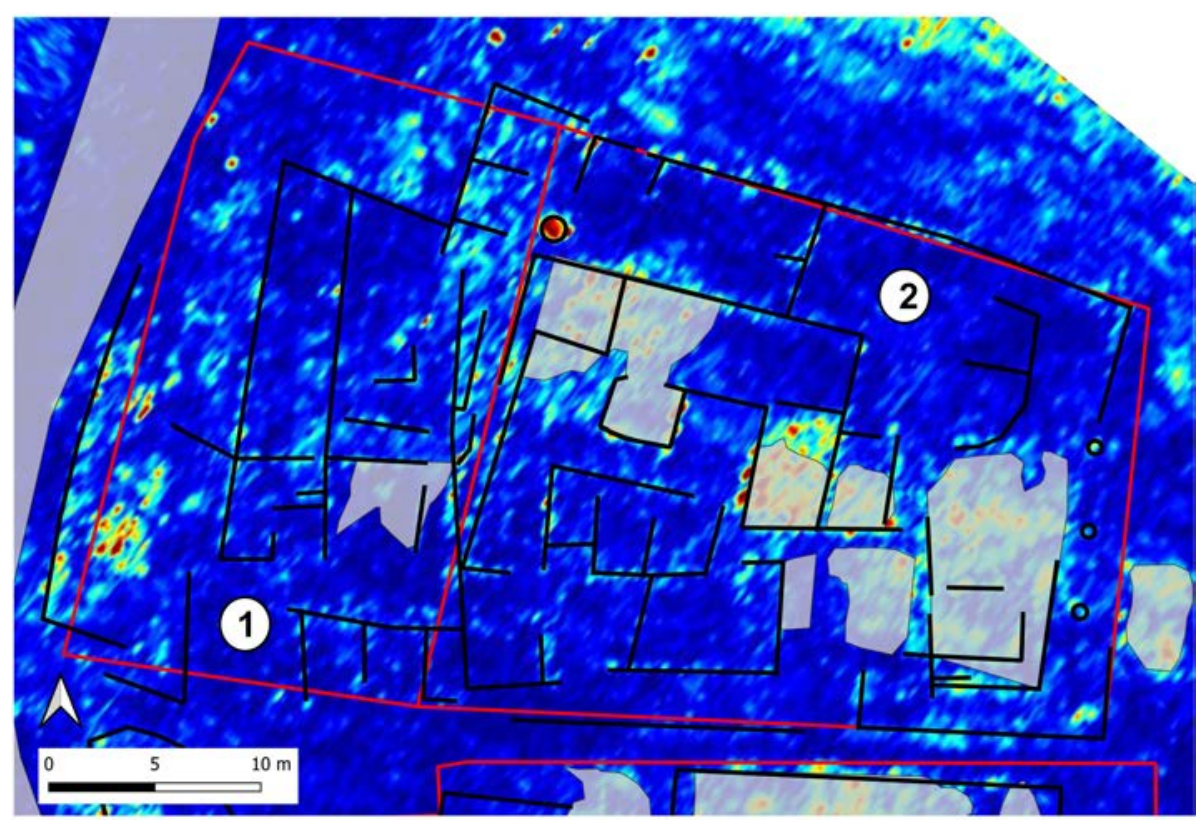

Figura 9 Interpretación de insulae 1 y 2

\subsubsection{Vía Segisamo-Pisoraca}

Nos hemos referido en numerosas ocasiones al trazado de esta vía, un ramal teóricamente secundario dentro de la estructura de comunicaciones peninsulares en época romana y que conecta la ciudad romana de Segisamo con Pisoraca (Herrera de Pisuerga, Palencia). 
La cercana relación y carácter limitáneo de estos dos núcleos es conocida gracias a la existencia de un terminus o mojón de época augustea (19 a.C.-14 d.C.) que divide las tierras de la legio IIII Macedonica, acantonada en Herrera de Pisuerga, del agger o territorio perteneciente a los Segisamonenses. Ese fenómeno ha sido objeto de varios estudios detallados, tanto desde la óptica de la epigrafía pública como de los procesos de ocupación y explotación del territorio (CORTÉS BARCENA, 2009) que se desencadenan con la llegada de Roma a la región.

El trazado de vía romana aparece de forma totalmente conspicua tanto en la fotografía aérea de diferentes coberturas (Figura 10) como en los datos de la prospección geofísica. Los valores de gran amplitud muestran tanto el posible nivel de circulación a una profundidad de $80-100 \mathrm{~cm}$ bajo la superficie como seguramente los niveles de preparación de los estratos de rudus y statumen típicos de este tipo de construcciones (Figura 11). Una pequeña excavación llevada a cabo por Moreno Gallo en la orilla izquierda del río Brullés, a escasos metros del puente de Trisla (MORENO GALLO 2011: 6-7) muestra parte de la construcción de la calzada, que se interpreta como un posible camino medieval o moderno construido sobre la cimentación romana.

En Veladiez es posible que conservemos el trazado original de la vía de época romana, pues esta discurre paralela al antiguo camino en uso durante las épocas medieval y moderna. Esto implica que el cruce de la vía sobre el río Brullés se produciría 52 metros aguas abajo del puente de Trisla, cuya factura no es en absoluto romana pese a la extendida creencia popular. De este modo, el camino medieval se desviaría del trazado romano en este punto para luego reintegrarse nuevamente en el mismo. Asimismo, tanto en los datos del georradar como en las fotografías aéreas es posible observar algunas líneas que discurren en paralelo al trazado de la calzada romana. Posiblemente se correspondan con zanjas de drenaje en dirección al río Brullés.

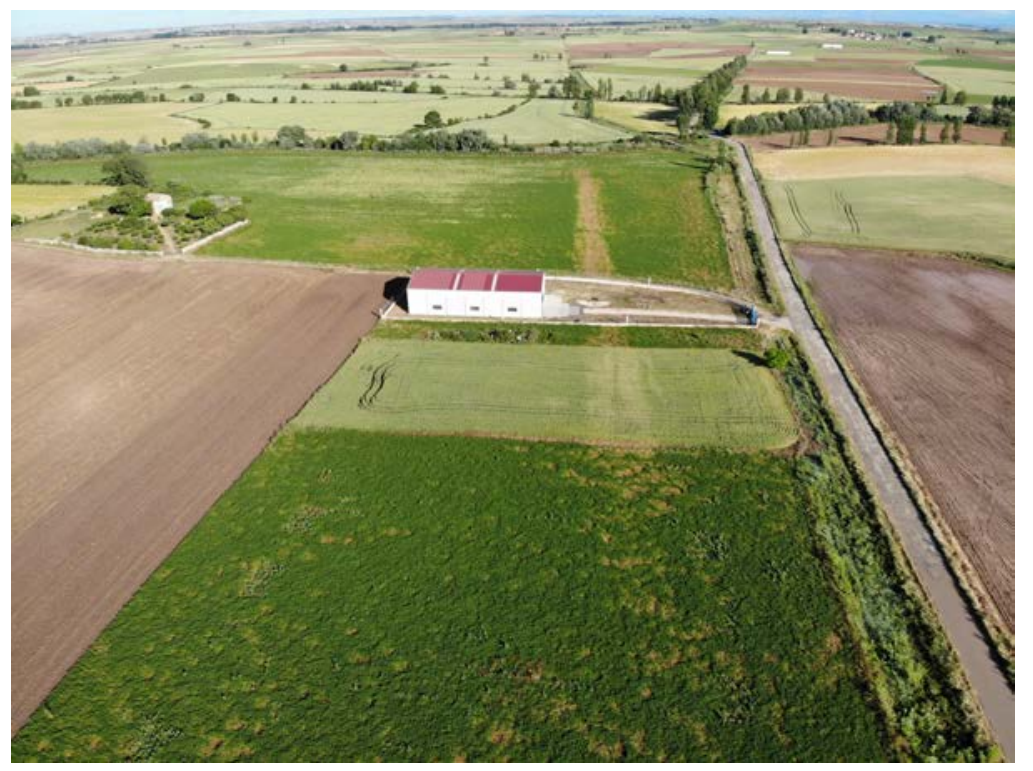

Figura 10. Trazado de la vía Segisamo-Pisoraca a su salida de Sasamón (06/06/2019). 


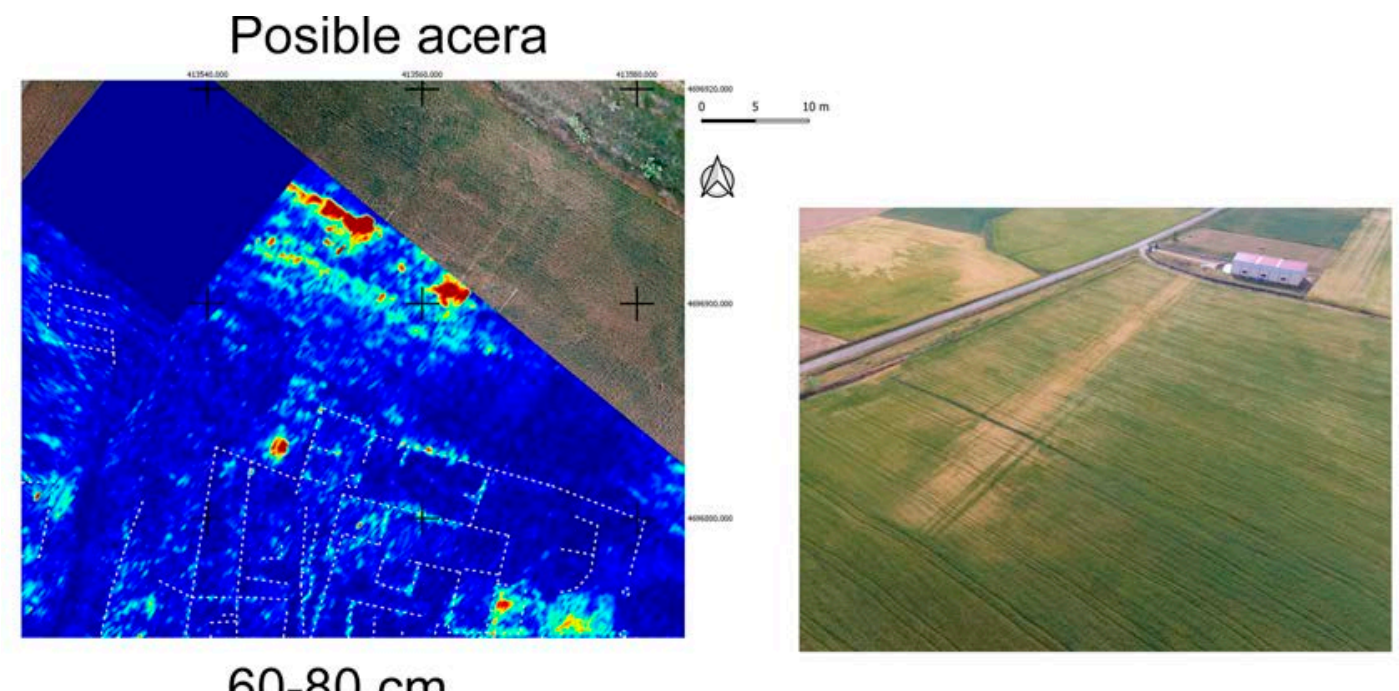

\section{Zona central de la calzada}

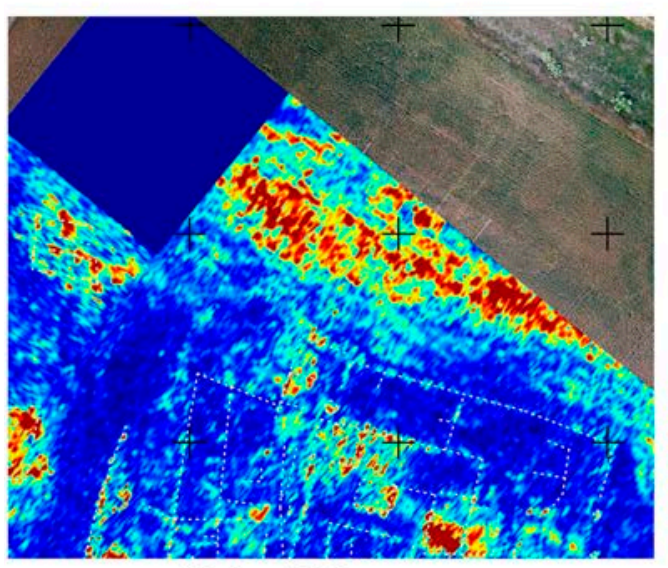

$100-120 \mathrm{~cm}$

\section{Preparación de la calzada}

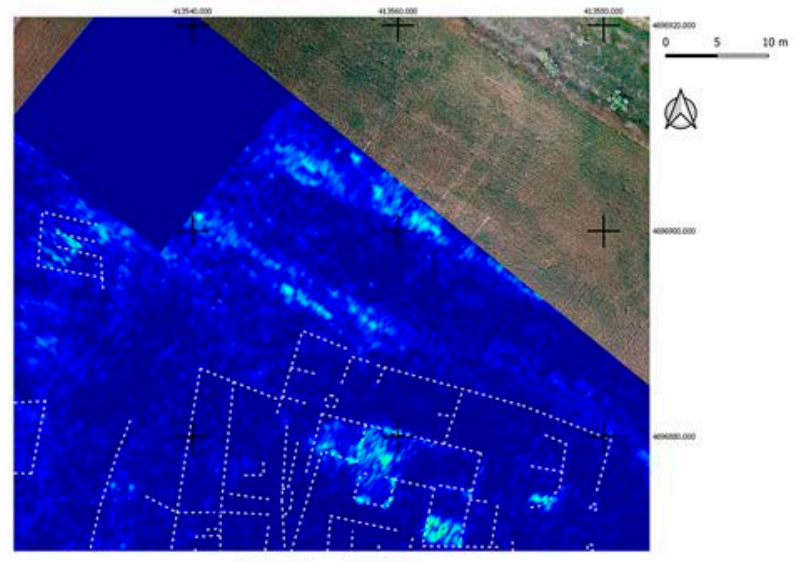

$160-180 \mathrm{~cm}$

Figura 11 Interpretación de la vía Segisamo-Pisoraca a diferentes profundidades.

\section{CONCLUSIONES}

La metodología de prospección no invasiva expuesta en este trabajo ha permitido documentar un sector desconocido de la ciudad romana de Segisamo. Esta iniciativa ha combinado de forma experimental distintos métodos y técnicas con el fin de maximizar la recopilación de información arqueológica. La planificación de varias coberturas de fotografía aérea con diversos medios y sensores y la prospección geofísica mediante georradar constituyen dos aproximaciones complementarias que nos permiten identificar y recrear con un elevado grado de precisión elementos soterrados a la espera de que la excavación arqueológica nos proporcione una secuencia estratigráfica a partir de la cual hacer una propuesta de periodización cronológica más precisa. 
Así pues, los resultados de ambos métodos han mostrado con claridad la presencia de varios bloques de viviendas insertos en el urbanismo romano de Segisamo. Uno de ellos puede interpretarse con un alto grado de seguridad como una vivienda unifamiliar de tipo domus, mientras que los otros dos bloques se han interpretado como insulae o espacios residenciales desarrollados en altura que contarían asimismo con establecimientos comerciales abiertos a la calle. Este hecho refleja la complejidad en el desarrollo del tejido urbano de la ciudad y la convivencia, al menos en el espacio, de estratos sociales teóricamente diferentes en la ciudad hispanorromana. La presencia de otra rica vivienda decorada con el mosaico del tritón, excavada por ABÁSOLO y GARCÍA (1993) en las inmediaciones de Veladiez refuerza esta interpretación.

Asimismo, hemos podido definir con mayor claridad el trazado urbanístico de este sector perimetral de la ciudad, identificándose con claridad el trazado de una vía romana y la existencia de un foso que limitaría el área perteneciente a la urbs propiamente dicha. A diferencia de lo que ocurre en otras ciudades romanas de la Meseta Norte similares (MARTÍNEZ CABALLERO et al. 2018), ni la prospección aérea ni la geofísica han permitido identificar una muralla delimitando el núcleo urbano. Finalmente, las estructuras documentadas nos permiten apuntar que existe una gran variación entre el urbanismo de época antigua y el que se desarrolla a partir de la época medieval, desdibujándose en gran medida el trazado de las calles y los espacios destinados al hábitat.

Pese a la gran fuerza que en el imaginario local tiene el pasado romano, esta fase de la historia de Sasamón sigue siendo en realidad bastante desconocida. El avance de la arqueología en la era digital y su facilidad para la incorporación de métodos y técnicas procedentes de otras disciplinas - a menudo con un bajo coste operativo- constituye una opción viable a la hora de revalorizar y dar a conocer el rico patrimonio arqueológico de las comunidades locales de la España vaciada.

\section{BIBLIOGRAFÍA}

Abásolo, J.A. 1975 Notas sobre el campamento romano de Sasamón (Burgos). Pyrenae $11,127-137$.

Abásolo, J.A., García, R. 1993 Excavaciones En Sasamón (Burgos). Madrid: Ministerio de Cultura, Instituto de Conservación y Restauración de Bienes Culturales.

Alarção, J. Etienne, R. 1977 Fouilles de Conimbriga I: L'architecture. Paris.

Arce Duarte, M. 1997 Mapa Geológico y Memoria de La Hoja No 199 (Sasamón). Mapa Geológico de España E. 1:50.000 ITGE. IGME.

Ariño E., Ezquerro, A., García Sánchez J, González-Tablas, J., Sala, R., Reyes de Soto, R. 2019 La ciudad de Libia (Herramelluri, España) y su territorio: arqueología del paisaje y prospección intensiva. Agri Centuriati 16, 117-138. https://doi.org/10.19272/201909101008 
Beltrán, M. 2003 La casa hispanorromana. Modelos. Bolskan: Revista de arqueología del Instituto de Estudios Altoaragoneses 20, 13-66.

Conyers, L.B. 2004 Ground-Penetrating Radar for Archaeology. Altamira Press, Walnut Creek.

Cortés Barcena, C. 2009 El territorio militar en la epigrafía de la Hispania Romana: los Termini Pratorum. Limes XX. Estudios sobre la frontera romana, pp. 91-102. CSIC. Ediciones Polifemo.

del Olmo, J. 2006 Arqueología Aérea de las Ciudades Romanas en la Meseta Norte. Algunos ejemplos de la primera Edad del Hierro, segunda Edad del Hierro y Romanización. Moreno Gallo I (ed.) Nuevos Elementos de Ingeniería Romana. III Congreso de Las Obras Públicas Romanas. Junta de Castilla y León. Consejería de Cultura y Turismo, 313-340.

Didierjean, F., Abásolo, J.A. 2007 La vía Aquitana. Aportaciones de la fotografía aérea. Navarro Caballero M, Palao Vicente JJ, and Magallón Botaya MÁ (eds) Villes et Territoires Dans Le Bassin Du Douro á l'époque Romaine: Actes de La TableRonde. Bourdeaux: Ausonius, 395-427.

Driver, T.G., Burnham, B.C., Davies, J.L. 2020 Roman Wales: Aerial Discoveries and New Observations from the Drought of 2018. Britannia 51, 1-29. https://doi.org/10.1017/S0068113X20000100

Fiz, I., Cuesta, R., Subias, E., Manuel Martín P. (2021) Tests with SAR Images of the PAZ Platform Applied to the Archaeological Site of Clunia (Burgos, Spain). Remote Sensing 13(12), 2344. https://doi.org/10.3390/rs 13122344

García Sánchez, J. 2012 Arqueología y paisaje en el noroeste de Burgos: la transición de la Segunda Edad de Hierro a época romana a través del registro material. Universidad de Cantabria, Santander. Available at: http://www.tdx.cat/handle/10803/80486 (accessed 24 April 2012).

García Sánchez, J. 2018 The hinterland of Segisamo. The landscape of a Roman city through off-site survey. I Wohlfarth, C., C. (eds) Funde in Der Landschaft. Neue Perspektiven Und Ergebnisse Archäeogischer Prospektion. Materialen zur Bodendenkmalpflege im Rheinland 26. Bonn: Fritz Thyssen Stiftung,181-192.

García Sánchez, J. 2020 Un posible conjunto termal en Segisamo (Sasamón). Primeros datos para su estudio. García Entero, V., Noguera Celdrán, M., and Pavia Page, M. (eds) Actas Del Congreso Internacional de Termas Públicas En Hispania. SPAL Monografias 33, 597-606.

García Sánchez, J. Costa-García, J.M. 2020 Del oppidum indígena a la ciudad romana. Evolución del paisaje de Segisamo (Sasamón, Burgos, España) a través de la fotografía aérea. Datos de la prospección aérea de 2019. Lucentum 39, 131-148. https://doi.org/10.14198/LVCENTVM2020.39.07

García Sánchez, J. Cisneros Cunchillos, M. 2013 An off-site approach to Late Iron Age and Roman landscapes in the Northern Plateau, Spain. European Journal of Archaeology 16, 289-313. https://doi.org/10.1179/1461957112Y.0000000027

Hidalgo Prieto, I., Carrasco Gómez, I., Hermann, F., Teichner, F. 2018 El proyecto de investigación arqueológica en la Cañada Honda de Italica. Planteamientos, objetivos y primeros resultados. Antiquitas (30), 45-61. 
Lagóstena Barrios, L. 2021 Estructuras de la ocupación rural romana en las campiñas hastenses y gaditanas: problemática y aportación de la exploración GPR a su conocimiento. Mayoral Herrera, V., Grau Mira, I., Bellón Ruiz, J.P. (eds.) Arqueología y Sociedad de Los Espacios Agrarios. En Busca de La Gente Invisible a Través de La Materialidad Del Paisaje. Anejos de AEspA XCI. Madrid: Archivo Español de Arqueología, 109-117.

Lasaponara, R. Masini, N. 2011 Satellite remote sensing in archaeology: past, present and future perspectives. Journal of Archaeological Science 38(9), 1995-2002. https://doi.org/10.1016/j.jas.2011.02.002

Martinez Caballero, S., J. Santos Yanguas, L. Municio González, L.J. (eds.) 2018. El Urbanismo Romano en el Valle del Duero. Actas de la I reunión de Ciudades Romanas Del Valle Del Duero. Segovia, 20 y 21 de Octubre de 2016. Asociación de amigos del Museo de Segovia. Segovia.

Moreno Gallo, I. 2011 Vía romana de Segisamone a Pisoraca. De Sasamón a Herrera de Pisuerga. Junta de Castilla y León.

O'Driscoll, J. 2018 Landscape applications of photogrammetry using unmanned aerial vehicles. Journal of Archaeological Science: Reports 22, 32-44. https://doi.org/10.1016/j.jasrep.2018.09.010

Salgado Carmona, J.Á., Quirós, E., Mayoral, V., Charro, C. 2020 Assessing the potential of multispectral and thermal UAV imagery from archaeological sites. A case study from the Iron Age hillfort of Villasviejas del Tamuja (Cáceres, Spain). Journal of Archaeological Science: Reports 31, 102312. https://doi.org/10.1016/j.jasrep.2020.102312

Sarris, A., Kalayci, T., Papadopoulos, N., Argyrou, N., Kakoulaki, G., Manataki, M., Papadakis, M., Nikas, N., Scotton, O., Kissas, K.2020 Geophysical explorations of the classical coastal settlement of Lechaion, Peloponnese (Greece). Dabas M, Campana S, and Sarris A (eds.) Mapping the Past from Sampling Sites and Landscapes to Exploring the 'Archaeological Continuum'. Oxford: ArchaeoPress, 43-52.

Schmidt, A., Linford, P., David, A., Gaffney, C., Sarris, A., Fassbinder, J. 2015 Guidelines for the Use of Geophysics in Archaeology: Questions to Ask and Points to Consider. Namur. Europae Archaeologia Consilium.

Seren, S., Eder-Hinterleitner, A., Neubauer, W., Löcker, K., Melichar, P. 2007 Extended comparison of different GPR systems and antenna configurations at the Roman site of Carnuntum. Near Surface Geophysics 5(6), 389-394. https://doi.org/10.3997/1873-0604.2007021

Teichner, F., Illaregui, E., Moreno Escobar, M.D.C., Hermann, F., Arribas Lobo, P.2021 'Ver lo invisible'. Prospecciones geofísicas en el yacimiento arqueológico de Tiermes (Montejo de Tiermes, Soria). Anejos de Oppidum 7, 105-123.

Verdonck, L., Taelman, D., Corsi, C., Vermeulen, F. 2012 Ground Penetrating Radar at Ammaia. In: AMMAIA I: The Survey. A Romano-Lusitanian Townscape Revealed. Ghent. Academia Press, 69-81.

Verdonck, L., Launaro, A., Vermeulen, F., Millet, M. 2020 Ground-penetrating radar survey at Falerii Novi: a new approach to the study of Roman cities. Antiquity 94(375), 705-723. https://doi.org/10.15184/aqy.2020.82 
Verhoeven, G. 2012 Near-Infrared Aerial Crop Mark Archaeology: From its Historical Use to Current Digital Implementations. Journal of Archaeological Method and Theory 19(1), 132-160. https://doi.org/10.1007/s10816-011-9104-5

Vermeulen, F., Hay, S., Verhoeven, G., Baldwin, E., Ferraby, R., Vedonck, L., Serrano, S. 2006 Potentia: An Integrated Survey of a Roman Colony on the Adriatic Coast. Papers of the British School at Rome 74, 203-236.

Waagen, J. 2019 New technology and archaeological practice. Improving the primary archaeological recording process in excavation by means of UAS photogrammetry. Journal of Archaeological Science 101, 11-20. https://doi.org/10.1016/j.jas.2018.10.011 